\title{
Sacroilitis paraneoplásica: presentación inusual de leucemia linfoblástica aguda
}

\author{
Paraneoplastic sacroiliitis: unusual presentation of acute lymphoblastic leukemia
}

José G. Solís* y Guillermo. Flores-Padilla

Servicio de Medicina Interna, Hospital de Especialidades, Centro Médico Nacional Siglo XXI, Instituto Mexicano del Seguro Social, Ciudad de México, México

\section{Resumen}

La sacroilitis es una manifestación poco común de neoplasias hematológicas. Reportamos el caso de una mujer de 40 años que presentó un cuadro de 1 mes de evolución con fiebre y sacroilitis simulando espondiloartritis, acompañado de anemia, hepatomegalia y elevación de marcadores inflamatorios. El abordaje descartó infecciones y causas inflamatorias de dolor sacroilíaco. Los hallazgos en la médula ósea llevaron al diagnóstico de leucemia linfoblástica aguda (LLA) de células B. Hasta donde sabemos, el presente es uno de los pocos casos publicados de LLA que se manifiesta con sacroilitis. La sacroilitis como manifestación inicial de LLA puede resultar en un diagnóstico erróneo, por lo que el diagnóstico diferencial es esencial cuando se encuentran presentes características atípicas.

Palabras clave: Fiebre de origen desconocido. Leucemia. Paraneoplásico. Sacroilitis.

\section{Abstract}

Sacroilitis is an uncommon manifestation of hematological malignancies. We herein report the case of a 40-year-old female that presented with a one-month-old history of fever and sacroilitis mimicking spondylarthritis, accompanied by anemia, hepatomegaly, and elevated inflammatory markers. Work-up ruled out infectious and inflammatory causes of sacroiliac pain. Bone marrow findings led to the diagnosis B-cell acute lymphoblastic leukemia (ALL). To the best of our knowledge, the current study represents one of the few published cases of ALL presenting with sacroilititis. Sacroilitis as an onset manifestation of ALL may result in misdiagnosis, therefore, a differential diagnosis is essential when atypical features are present.

Key words: Fever of unknown origin. Leukemia. Paraneoplastic. Sacroiliitis.

\section{Introducción}

La sacroilitis se define como la inflamación de la articulación sacroilíaca. Esta puede presentarse en numerosas enfermedades infecciosas, reumatológicas y neoplásicas ${ }^{1}$. La sacroilitis como síndrome reumatológico asociado a cáncer se reporta de forma infrecuente y ha sido descrita principalmente en neoplasias hematológicas ${ }^{2}$. Presentamos el caso de una paciente con un cuadro de sacroilitis secundaria a leucemia linfoblástica aguda (LLA).

\section{Correspondencia:}

*José G. Solís

Avda. Cuauhtémoc, 330

Col. Doctores, Del. Cuauhtémoc

Fecha de recepción: 20-04-2020

C.P. 06720, Ciudad de México, México

E-mail: gabrielsolismd@ gmail.com

(http://creativecommons.org/licenses/by-nc-nd/4.0/).
Fecha de aceptación: 31-07-2020

DOI: 10.24875/CIRU.20000366
Cir Cir. 2020;88(S2):71-74

Contents available at PubMed www.cirugiaycirujanos.com 


\section{Caso clínico}

Mujer de 40 años que ingresó a nuestro servicio con un cuadro clínico de 1 mes de evolución caracterizado por fiebre de predominio vespertino, diaforesis y dolor intenso en la espalda baja y la articulación sacroilíaca bilateral. El dolor tenía características inflamatorias y limitaba sus actividades de la vida diaria. Ella trabajaba como médico y no contaba con enfermedades de base. No había otros datos relevantes en su historia clínica. A la exploración física solo destacaban pruebas de Patrick y Gaenslen positivas. Los laboratorios de ingreso mostraron anemia de $9.2 \mathrm{~g} / \mathrm{dl}$ con recuento leucocitario y plaquetario normal, lactato deshidrogenasa de $6062 \mathrm{UI} / \mathrm{l}$, hiperferritinemia de $1452 \mathrm{ng} / \mathrm{ml}$ y reactantes de fase aguda elevados (velocidad de sedimentación globular 28 $\mathrm{mm} / \mathrm{h}$ y proteína $\mathrm{C}$ reactiva $41 \mathrm{mg} / \mathrm{dl}$ ). No presentaba alteraciones en el panel inmunológico. Las radiografías y las tomografías computarizadas (TC) de columna y pelvis eran normales. Una TC toracoabdominal demostró hepatomegalia. Se realizó un gammagrama

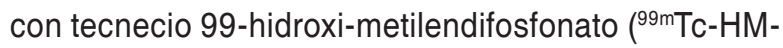
DP) que documentó captación bilateral en la articulación sacroilíaca compatible con sacroilitis (Fig. 1 A). Inicialmente se sospechó brucelosis aguda, por lo que se solicitó serología y se inició una prueba terapéutica con doxiciclina; sin embargo, los estudios fueron negativos. No se encontró evidencia de neoplasia hematológica en el frotis ni en la citometría de flujo de sangre periférica. Se intentó realizar un aspirado de médula ósea, el cual fue fallido por extracción seca. Por la alta sospecha diagnóstica se solicitó una tomografía por emisión de positrones (PET) con 18-fluorodesoxiglucosa ( $\left.{ }^{18} \mathrm{FDG}\right)$, en la cual se encontró un incremento anormal de la captación en la médula ósea de forma difusa, especialmente en la columna lumbar (Fig. 1 B). Con estos hallazgos se decidió realizar una biopsia de hueso guiada por TC a nivel de L4. El estudio histopatológico reportó una medula ósea con un $90 \%$ de infiltración neoplásica linfoide CD 20+ PAX-5+ CD10+ CD3- MPO- y mielofibrosis de grado 2, concluyendo el diagnóstico de LLA tipo B. Durante su evolución a corto plazo, la paciente desarrolló pancitopenia con elevación importante de la lactato deshidrogenasa hasta 12,000 UI/I y evidencia de linfoblastos en sangre periférica. La paciente actualmente recibe esquema de quimioterapia para inducción a la remisión, con planes de realizar trasplante de médula ósea como consolidación.

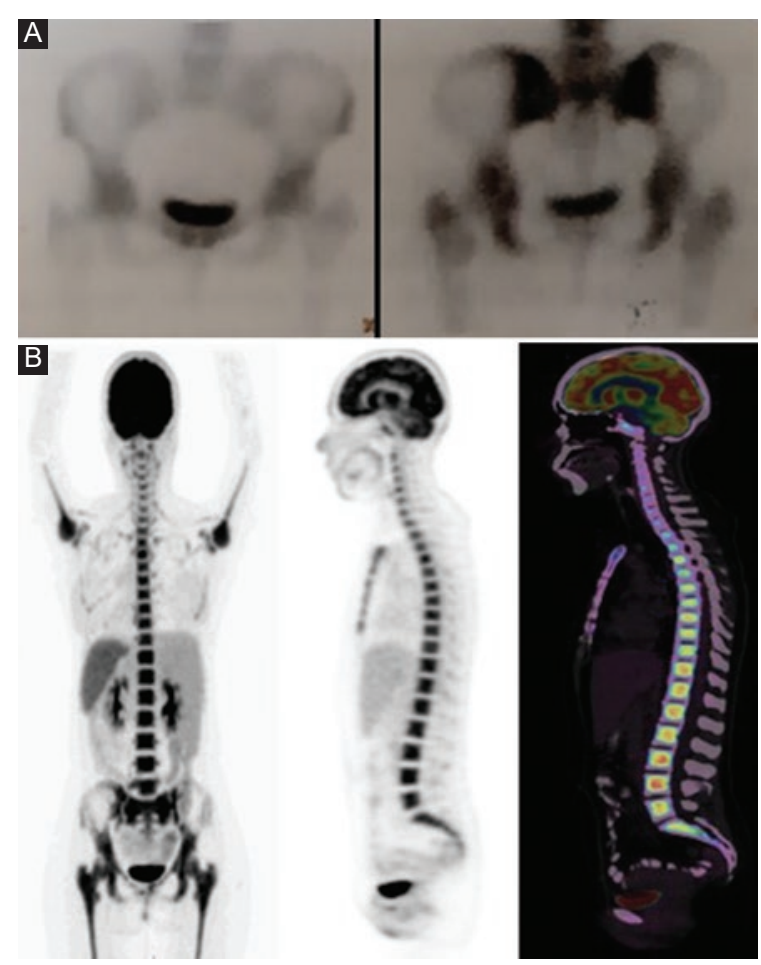

Figura 1. A: centellografía ósea con ${ }^{99 m} T c-H M D P$ con evidencia de proceso inflamatorio en articulación sacroiliaca bilateral. B: tomografía por emisión de positrones con ${ }^{18} \mathrm{FDG}$ que muestra un incremento anormal de la captación en la médula ósea de forma difusa.

\section{Discusión}

La LLA es la segunda leucemia más común en los adultos. El dolor óseo es un síntoma infrecuente en este grupo de edad, y la presentación clínica con un síndrome reumatológico bien definido es sumamente rara. En una cohorte de 139 pacientes con leucemia aguda solo $8(5.8 \%)$ tuvieron manifestaciones reumatológicas que precedieron al diagnóstico. Los datos asociados a una etiología neoplásica fueron dolor intenso no compatible con la exploración física, falta de respuesta al tratamiento farmacológico, osteopenia y lesiones líticas óseas ${ }^{3}$.

Los síndromes reumatológicos asociados a neoplasias pueden ser secundarios a infiltración directa 0 mediados por factores inflamatorios secretados a distancia por las células tumorales ${ }^{4}$. La sacroilitis aguda como parte de estos fenómenos solo se encuentra descrita de forma anecdótica. Cohen, et al. ${ }^{5}$ documentaron el primer caso de sacroilitis paraneoplásica en una mujer de 61 años que desarrolló espondiloartritis rápidamente progresiva asociada a un linfoma linfocítico. Existen solo cuatro casos reportados de 
Tabla 1. Casos reportados en la literatura de sacroilitis como forma de presentación de leucemia aguda en adultos

\begin{tabular}{|c|c|c|c|c|c|}
\hline Autor y año & Características clínicas & $\begin{array}{l}\text { Hallazgos de } \\
\text { laboratorio }\end{array}$ & $\begin{array}{l}\text { Diagnóstico por } \\
\text { imagen }\end{array}$ & $\begin{array}{l}\text { Diagnóstico } \\
\text { hematológico }\end{array}$ & $\begin{array}{l}\text { Respuesta al } \\
\text { tratamiento }\end{array}$ \\
\hline $\begin{array}{l}\text { Moghadam, et al., } \\
2010^{6}\end{array}$ & $\begin{array}{l}\text { Hombre de } 17 \text { años } \\
\text { Dolor en espalda baja, } \\
\text { inflamatorio, artritis de } \\
\text { ambas rodillas } \\
\text { Varios meses de evolución }\end{array}$ & $\begin{array}{l}\text { Pancitopenia PCR y } \\
\text { VSG elevadas }\end{array}$ & $\begin{array}{l}\text { TC: sacroilitis } \\
\text { izquierda }\end{array}$ & LLA & $\begin{array}{l}\text { Remisión completa de } \\
\text { LLA y mejoría de la } \\
\text { sacroilitis }\end{array}$ \\
\hline Esen, et al., $2011^{7}$ & $\begin{array}{l}\text { Mujer de } 41 \text { años } \\
\text { Dolor en espalda baja y } \\
\text { pierna izquierda } \\
1 \text { año de evolución }\end{array}$ & $\begin{array}{l}\text { Anemia y } \\
\text { trombocitopenia } \\
\text { VSG y PCR } \\
\text { elevadas }\end{array}$ & $\begin{array}{l}\text { RM: sacroilitis bilateral } \\
\text { Centellografía ósea: } \\
\text { sacroilitis izquierda }\end{array}$ & LLA (L3) & Resolución de sacroilitis \\
\hline $\mathrm{Xu}$, et al., $2016^{8}$ & $\begin{array}{l}\text { Hombre de } 18 \text { años } \\
\text { Dolor en espalda baja y } \\
\text { rodilla izquierda Fiebre } \\
\text { Esplenomegalia } \\
4 \text { meses de evolución }\end{array}$ & $\begin{array}{l}\text { Anemia, } \\
\text { trombocitopenia y } \\
\text { neutropenia } \\
\text { VSG y PCR } \\
\text { elevadas }\end{array}$ & $\begin{array}{l}\text { TC: erosión bilateral } \\
\text { de articulaciones } \\
\text { sacroilíacas }\end{array}$ & LLA pre-B & $\begin{array}{l}\text { Remisión completa de } \\
\text { LLA y sacroilitis }\end{array}$ \\
\hline Garg, et al., $2017^{9}$ & $\begin{array}{l}\text { Mujer de } 46 \text { años } \\
\text { Dolor en espalda baja y } \\
\text { debilidad generalizada } \\
8 \text { meses de evolución }\end{array}$ & $\begin{array}{l}\text { Anemia y } \\
\text { trombocitopenia } \\
\text { VSG y PCR } \\
\text { elevadas }\end{array}$ & RM: sacroilitis bilateral & LLA & Mejoría del dolor \\
\hline Hoshino, et al., $2006^{10}$ & $\begin{array}{l}\text { Mujer de } 27 \text { años } \\
\text { Dolor en cadera derecha } \\
\text { Oligoartritis de falanges de } \\
\text { pie y tobillo derecho } \\
3 \text { meses de evolución }\end{array}$ & $\begin{array}{l}\text { Anemia y } \\
\text { leucocitosis } \\
\text { VSG y PCR } \\
\text { elevadas }\end{array}$ & $\begin{array}{l}\text { RM y centellografía } \\
\text { ósea: sacroilitis } \\
\text { bilateral }\end{array}$ & $\begin{array}{l}\text { Anemia } \\
\text { refractaria con } \\
\text { exceso de } \\
\text { blastos } \\
\text { LMA }\end{array}$ & $\begin{array}{l}\text { Mejoría de la sacroilitis } \\
\text { Recurrencia y } \\
\text { progresión de LMA } \\
\text { Muerte }\end{array}$ \\
\hline Mondal, et al., $2016^{11}$ & $\begin{array}{l}\text { Hombre de } 27 \text { años } \\
\text { Dolor de espalda baja } \\
\text { Artritis de tobillos y rodillas } \\
1 \text { semana de evolución }\end{array}$ & $\begin{array}{l}\text { Anemia y } \\
\text { trombocitopenia } \\
\text { VSG y PCR } \\
\text { elevadas }\end{array}$ & RM: sacroilitis bilateral & LMA & No especifica \\
\hline
\end{tabular}

LLA: leucemia linfoblástica aguda; LMA: leucemia mieloide aguda; PCR: proteína C reactiva; RM: resonancia magnética; TC: tomografía computarizada; VSG: velocidad de sedimentación globular.

sacroilitis como forma de presentación de LLA ${ }^{6-9}$. Además, se encuentran dos casos reportados en pacientes con leucemia mieloide aguda ${ }^{10,11}$. En la tabla 1 se muestra una comparación de los casos reportados en la literatura.

Todos estos casos eran pacientes jóvenes, con un rango de edad de 17 a 46 años. El cuadro clínico fue de dolor en la espalda baja de características inflamatorias con una evolución subaguda a crónica en todos los pacientes, en algunos asociado a artritis. Todos los pacientes cursaron con citopenias y elevación de la velocidad de sedimentación globular y de la proteína $\mathrm{C}$ reactiva. La sacroilitis respondió al tratamiento dirigido a la neoplasia hematológica.

En todos estos reportes, el diagnóstico de leucemia aguda se hizo tras un aspirado de médula ósea de forma estándar, lo cual no fue posible en nuestra paciente, ya que se obtuvo una extracción seca, probablemente debido a la mielofibrosis asociada. Esto representó un reto diagnóstico y, guiados por la sospecha clínica, nos llevó a solicitar una PET con ${ }^{18} \mathrm{FDG}$.
Esta circunstancia puede explicar por qué el tiempo de presentación previo al diagnóstico en nuestra paciente fue significativamente menor que el reportado en la literatura.

El papel de la PET con ${ }^{18} \mathrm{FDG}$ en el abordaje de las leucemias agudas se encuentra documentado en el diagnóstico temprano de aquellos casos con presentaciones atípicas, como pacientes con leucemias aleucémicas, aquellos con incapacidad para obtener un aspirado de medula ósea o en presencia de fiebre de origen desconocido ${ }^{12,13}$. En nuestro caso, fue fundamental para llegar al diagnóstico.

\section{Conclusiones}

La sacroilitis representa una forma inusual de presentación de las leucemias agudas en los adultos. Los casos reportados en la literatura son en pacientes jóvenes, con una evolución subaguda-crónica, acompañadas por citopenias y elevación de los reactantes de fase aguda. Una centellografía ósea o una resonancia 
magnética pueden confirmar la sacroilitis. El diagnóstico requiere un aspirado de medula ósea, pero la biopsia guiada por PET tiene utilidad en los casos de leucemia aleucémica o mielofibrosis asociada. Esta suele mejorar con el tratamiento de la neoplasia hematológica.

\section{Conflictos de intereses}

Los autores declaramos no tener conflictos de intereses.

\section{Financiamiento}

La presente investigación no ha recibido ayudas específicas provenientes de agencias del sector públi$c o$, sector comercial o entidades sin ánimo de lucro.

\section{Responsabilidades éticas}

Protección de personas y animales. Los autores declaran que para esta investigación no se han realizado experimentos en seres humanos ni en animales.

Confidencialidad de los datos. Los autores declaran que han seguido los protocolos de su centro de trabajo sobre la publicación de datos de pacientes.
Derecho a la privacidad y consentimiento informado. Los autores han obtenido el consentimiento informado de los pacientes y/o sujetos referidos en el artículo. Este documento obra en poder del autor de correspondencia.

\section{Bibliografía}

1. Slobodin G, Rimar D, Boulman N, Kalt L, Rozenbaum M, Rosner I, et al. Acute sacroiliitis. Clin Rheumatol. 2016;35:851-6.

2. Naschitz JE, Rosner I, Rozenbaum M, Zuckerman E, Yeshurun D. Rheumatic syndromes: clues to occult neoplasia. Semin Arthritis Rheum. 1999;29:43-55.

3. Gur H, Koren V, Ehrenfeld M, Ben-Bassat I, Sidi Y. Rheumatic manifestations preceding adult acute leukemia: characteristics and implication in course and prognosis. Acta Haematol. 1999;101:1-6.

4. Manger B, Schett G. Paraneoplastic syndromes in rheumatology. Nat Rev Rheumatol. 2014;10:662-70.

5. Cohen MR, Carrera GE, Lundberg J. Rapidly progressive sacroiliitis in a patient with lymphocytic lymphoma. Ann Rheum Dis. 1993;52:239-40.

6. Moghadam A, Talebi-Taher M, Dehghan A. Sacroiliitis as an initial presentation of acute lymphoblastic leukaemia. Acta Clin Belg. 2010;65:197-9.

7. Esen BA, Özer L, Kamalı S, İnanç M. A prodrome of acute lymphoblastic leukemia mimicking sacroiliitis. Eur J Gen Med. 2011;8:151-3.

8. Xu D, Xu G, Xu L, Cao H, Xu B, Chen W, et al. Acute lymphocytic leukemia mimicking spondyloarthritis in an adolescent: a case report and review of the literature. Oncol Lett. 2016;11:1143-5.

9. Garg G, Chawla N, Gogia A, Kakar A. Low backache in adults as an initial presentation of acute lymphoblastic leukemia. J Fam Med Prim Care. 2017;6:434

10. Hoshino T, Matsushima T, Saitoh Y, Yamane A, Takizawa M, Irisawa H, et al. Sacroiliitis as an initial manifestation of acute myelogenous leukemia. Int J Hematol. 2006;84:421-4.

11. Mondal S, Sinha D, Ete T, Goswami RP, Bardhan J, Ghosh A. A Foe incognito: paraneoplastic sacroilitis. J Med Cases. 2016;7:341-3.

12. Arslan F, Yilmaz M, Cakir T, Mert A. Significant contribution of fluorodeoxyglucose positron emission tomography/computed tomography (FDG PET/CT) in a case of acute lymphoblastic leukemia presenting with fever of unknown origin. Intern Med. 2014;53:789-91.

13. Tokmak H, Ergonul O. The evolving role of PET/CT in fever of unknown origin. Int J Infect Dis. 2014;27:1-3. 